\title{
Region Innovation Potential as a Factor of Sustainable Development
}

\author{
Andrey Kopein ${ }^{1,}$, Kseniya Demidenko ${ }^{2}$, Olga Fattakhova $^{2}$, Tamara Frolova $^{2}$, Valeriy \\ Lovchikov $^{2}$, and Irina Shurchanova ${ }^{2}$ \\ ${ }^{1}$ International Institute of Economics and Law, Siberian branch, Pirogova st., 9, Novokuznezk, Russia \\ ${ }^{2}$ Kemerovo institute (branch) of Plekhanov Russian University of Economics, Department of Finance \\ and banking, Kuznetsky pr., 39, Kemerovo, Russia
}

\begin{abstract}
The article deals with the theoretical and practical issues of innovation activity as a factor of economic development and its sustainability. It reveals that economic instability can affect the investment climate, as well as cause significant slowdown of the innovation process. It points out the differences in adaptation processes in regions, which are reflected in the pace and direction of innovation implementation. An assessment of the innovation potential of a resource-type region was carried out based on indicative method and a set of criteria which were divided into five groups. The groups are formed according to scientific, technical, personnel, financial and resulting components. The analysis revealed that the resulting component is in a pre-crisis state, which is determined by the small number of active enterprises introducing innovation technologies and a small share of innovative products. It was noted that the technical and personnel components are in a normal state, and the financial component is in the state of crisis. It was concluded that there exists a sufficiently high innovation potential in the basic sectors of the industrial region. The debatable results of any assessments of the innovation potential and its impact on the sustainability of socio-economic development are underlined.
\end{abstract}

\section{Introduction}

The search for a new model for the Russia's development of, conducted by many scientists and experts, to some extent contains elements of innovation policy. Scientists agree that nowadays the high-order technological mode predominates in the development of the civilization, which contributes to the effective use of all types of resources as well as minimizes the ecosystem load. The academia (economic communities in particular) continue discussing the influence of all factors on the direction, as well as the rate, of socioeconomic development and its sustainability $[1,2,3]$. Additional issues arise when studying the impact of economic sanctions on the Russian economy, which is often viewed controversially $[4,5,6]$.

\footnotetext{
${ }^{*}$ Corresponding author: valkem2@mail.ru
} 
In the context of economic instability, the development of high-tech production in all sectors of Russian national economy, as well as of other countries' ones, contributes to maintaining its competitiveness globally. It raises the level of national security and its components (food, economic, financial and others) $[7,8]$ in addition to expanding the investment, which, in turn, is inseparable from active implementation of innovations requiring specific conditions in regions, especially for import substitution [9, 10]. As a factor influencing the investment process in Russia, import substitution policy is turning into a long-term strategy of economic development being a natural reaction to changes in external and internal economic and political conditions.

For Russia import substitution cannot become insurance against all risks, but it is a priority that investors should be guided by, when investing in the energy sector, the coal industry or other industries [11,12]. This factor is becoming more and more significant for investing decisions. At the same time, the critical factor is: investors desire not only to minimize risks and maximize profits, but also to choose the most attractive implementation options.

One faces several theoretical and practical issues, when analyzing regions' adaptation to modern operational environment and activation of the investment process in the regions of diverse economy structure. Studying this process and its connection with the financial security of the region poses a scientific challenge which can be resolved by devising a regional policy system with its innovation, investment and financial aspects. The issue of financial security is still open for discussion.

\section{Materials and Methods}

The research is based on the dialectical approach to studying economic processes and phenomena. The object of the research is the industry-oriented Kemerovo region as a typical representative of the modern Russian economy of the crisis and post-crisis periods. The subject of the research is the innovative component of the regional economy, which is considered a factor of sustainable socio-economic development.

Chronologically, the period examined in the research is limited by a period of 20132017. It reflects all the characteristics of economic life under the conditions of economic instability. In our opinion, this period enables us to identify the main characteristics of the phenomenon as a reflection of the cause and effect relationship. Therefore, in order to obtain reliable scientific knowledge, the use of historical and evolutionary methods seems quite reasonable. Associating research on innovation activity with the periods of global economic crisis is logical and objective. The application of the historical method is also based on axiomatic acceptance of the evolutionary development of the economy. This is a characteristic of the dialectical approach, which is undoubtedly the only scientific approach to studying of economic phenomena in dynamics.

Such methods of abstraction as analysis and synthesis are used at the theoretical level of cognition. Applying these methods helps consider the phenomena in conjunction with other elements, as well as highlight the most essential features without reducing the accuracy of the study.

Relying on empirical knowledge, substantiated by the use of specific statistical data, the shift from empirical to theoretical is carried out with the help of mathematical modeling and econometric methods. Uniting the data in a mathematically comparable base, to a single coordinate system enables comparison, summarizing and moving to the next cognitive level. Applying the method, which proposes the move from abstract to concrete thinking reveals the innovation potential of the region with the accuracy, sufficient for the analysis. 
The complicated nature of determining the parameters of innovation activity seems to be of methodological complexity. The set of indicators chosen by the authors cannot be considered to meet the requirements of scientific research substantially. However, it reveals the phenomenon under consideration with minimal costs and sufficient representativeness.

\section{Results and Discussion}

In the context of economic instability, some production and service enterprises are adapting to new conditions by increasing their innovation activity. Import substitution combined with innovation activity has been fruitful, especially in Russian agro-industrial complex. Relatively small, but stable growth of volumetric and financial indicators illustrates this advancing trend, and, at the same time, it affects positively the overall understanding of sustainable development.

The investment activity in a particular region to a variable extent is influenced by the location of productive forces, geography, climate, significant differentiation in socioeconomic development of regions, industrial potential, as well as available natural, labor, financial and intellectual resources. Therefore, the structural policy, whose main direction is determined by the need for import substitutes, should be differentiated depending on the specific conditions for each particular region. This is reflected in investment climate and innovation activity in the Kemerovo region.

The technological cluster (Technopark) is operating effectively in Kuzbass. It plays the role of a catalyst for the region's innovation activity as well as for creating the infrastructure for innovative enterprises, namely the Regional engineering center and the Center for social innovations. At present, several investment projects concerning building industrial parks in Kemerovo, Novokuznetsk, Yurga, Kaltan, and Kiselevsk are being considered. The necessary regulatory framework is being developed, both at the regional and local levels.

In the field of lawmaking, in particular, it is planned to establish criteria for large-scale investment projects, implementation of which allows leasing land to legal entities without any tenders. Another project being developed in Kemerovo is about applying a reduction factor when calculating the rent for land provided for industrial parks.

What seems to be of great importance currently is a comprehensive analysis of the factors affecting the effectiveness of innovative systems. There are many approaches to the development of innovative performance indicators. A significant part of the indicators is developed by experts, which implies certain subjectivity in the estimation process. Nevertheless, averaging experts opinions and using them in modeling makes objective identification of trends possible. The state of innovation development directly reflects the economic climate in regions as well as in the whole country. Making managerial decisions requires defining the factors affecting the innovative development of the region. Econometric models, the multiple regression model, in particular, enable coping with this task. The analysis presented in the article reveals the correlation between the amount of investments in fixed capital, the number of employees engaged in research, and the volume of innovative products.

The analysis of the Kemerovo region innovation potential was carried out with the help of the algorithm consisting of several stages. The first stage determined the indicators characterizing the resource and productive components of the innovation potential. In order to estimate the innovative potential more reliably, five blocks of indicators were used: personnel, scientific, technical and technological, financial and resultant ones. The first block of indicators determined the conditions for ensuring innovative development, while the fifth block summarized the results of innovation activity. 
At the second stage, a regulatory model of the innovative potential state was formed. Next, the levels of crisis were considered, which is customary for applying indicative methods in research. Three levels of crisis were identified, the transition between those being based on defining threshold values. The three levels are normal, pre-crisis and crisis states. Normal state is characterized by a high or medium level of innovation potential. Precrisis state must be balanced in ways (organizational, technical, tax, etc.) aimed at increasing the level of innovation activity. Crisis state can be considered as requiring immediate measures of influence in order to promptly correct the situation and preserve the economy and society.

Table 1. Normative assessment model of the region's innovation potential

\begin{tabular}{|c|c|}
\hline $\begin{array}{c}\text { Kind of } \\
\text { inequality }\end{array}$ & $\begin{array}{c}\text { Characteristics of innovation } \\
\text { potential state }\end{array}$ \\
\hline $\mathrm{I} \geq \mathrm{L} 1$ & normal state \\
\hline $\mathrm{L} 1<\mathrm{I}<$ & pre-crisis state \\
$\mathrm{L} 2$ & crisis state \\
\hline $\mathrm{I} \leq \mathrm{L} 2$ & \\
\hline
\end{tabular}

I - criterion characterizing resource and resulting component of the innovation potential;

L1 - threshold value of the innovation potential indicator, which determines the boundary of pre-crisis state;

L2 - threshold value of the innovation potential indicator, which determines the limit of minimum acceptable level of the system crisis state.

Personnel component of the region is in good condition. This is illustrated by the indicators of 2015-2017, which are higher than 1. Eventually, these indicators increase, so their innovative potential increases respectively.

The scientific component consists of three blocks, each playing a specific role in determining the innovation potential. The ratio of workers is estimated to be in the crisis state, as evidenced by the negative values of the indicator. In 2015 it starts increasing and shifting towards the crisis state. The ratio of postgraduate and doctoral students, conducting researches, is in the pre-crisis state. This indicator demands steps being taken to prevent its deterioration and further fall into crisis. The ratio of the average salary in the science sector, as well as the previous indicator, are currently in the pre-crisis state. This marker is less than 1 , but more than zero. In general, the scientific component is in the pre-crisis state requiring urgent and effective stabilization measures.

The technical component, as well as all the other ones, consists of three main blocks. On average, the degree of fixed assets depreciation is assessed as normal, but the level of this indicator is rather high for a number of industries and enterprises. In general, this indicator requires be maintained at the current level. The rate of fixed assets renewal, as well as the previous factor, remains in a normal state. The ratio of machinery and equipment cost in the total amount of finance is used in the technical component as another indicator. It defines the state of the "science and scientific services" sector as a pre-crisis one. The foregoing shows that the technical component is in a normal state, and requires only supporting measures.

The financial component includes a share of the research costs and is in a pre-crisis state, whereas the current internal basic research costs are in a normal state. The share of innovation costs is negative, therefore lying in a crisis zone. However, specific measures are required to improve the situation. Internal current expenses involved in basic research are assessed as being in good condition, consequently, they should be maintained at the required level. The share of innovation spending in the total industrial output is in the state of crisis. 
The resulting component is finalized in the analysis under consideration. Rather small is the share of innovative products in the total volume of industrial products, as well as the share of innovatively active enterprises in the total number of industrial enterprises. This situation is considered to be a profound crisis. The number of innovatively active enterprises ought to be increased, since the existing share does not allow solving issues of expanding the innovative potential of the region. Government support can help these enterprises improve the situation. Nevertheless, the share of advanced production technologies used in the basic industries of Kuzbass is significant, which indicates this situation referring to this index as normal.

In general, it can be concluded that all the indicators considered in the research, demonstrate prevalence of a normal state of innovation potential. It illustrates the welldeveloped conditions for innovation activity in the Kemerovo region. However, there are also indicators that require consideration. They ought to be increased since they characterize the existing situation as a crisis.

The main goals of the socio-economic development of any region or state are improving the population's well-being and stabilizing the economy performance. This leads to increasing competitive advantages of the region, improving economy structure, as well as investment climate. For the Kemerovo Region, the main driver of socio-economic development is industry, mostly metallurgy, coal and chemical industries. Applying innovations to these sectors will inevitably lead to qualitative changes in related industries, which are forced to comply with new technologies of leading industries.

The willingness of such enterprises, industries, industrial region to imply innovations, their potential is high. However, one of the problems of assessing the innovation potential as a factor of sustainable development is its positioning at the regional level. The Kemerovo region economy is based on industrial sectors characterized by high capital intensity. Great potential lies in the deep processing of coal and transforming it into products which cost ten and hundred times higher than coal itself. Applying the results of scientific research, coal can be transformed into 130 types of semi-finished chemical product and more than 5,000 types of products for related industries: diesel fuel, medicines, fertilizers, benzenes, phenols, cresols, sorbents, fibers, building materials, and even cosmetics. Many products of basic necessity can be manufactured from the resources extracted in the region. This determines the high level of spending on innovation associated with the points of innovation activity growth outside the region, in federal centers of Russia. These federal centers are financial sources of the innovation activity and the residence of large enterprise owners.

\section{Conclusion}

Nowadays, the system assessing the innovation potential does not take into account the specifics of the particular region. There is no assessment methodology adapted to these features. The existing techniques are universal, but there cannot be a unified approach to assessing all regions. In this regard, all assessments of the innovation potential will be disputable. This, however, increases the value of the results as an impetus to the discussion and search for correct solutions. The presented results are debatable. It is necessary to conduct an in-depth study of the correlation of the region's innovative potential with the sustainability of economic development criteria, which are still not integrated in nor approved by the scientific community as the most appropriate combination of assessment factors. 


\section{References}

1. D. Rodric, Journal of Economic Growth, 21:1, 1-33 (2016)

2. O.L. Larson, The Economist, 21, 27 (2012)

3. M. Muro, The Avenue, 7, 21 (2016)

4. D. Gros, F. Mustilli, The effects of sanctions and counter-sanctions on EU-Russian trade flows (CEPS, Brussels, 2016).

5. Sanctions: how and when the EU adopt restrictive measures (FDFU, Brussels, 2017)

6. S. Secrieru, Russia under sanctions: Assessing the damage, scrutinising adaptation and evasion (Polski Instytut Spraw Miedzynarodowych, Warszawa, 2015)

7. V. Kopein, E. Filimonova, T. Sinitsyna, T. Lantseva, N. Morozenko, E3S Web Conf., 41, 04038 (2018)

8. M. Rodrigues, Journal of Monetary Economics, 57 :2, 175-188 (2010)

9. IMF World economic outlook. Seeking sustainable growth: Short-term recovery, longterm challenges (International Monetary Fund, Washington, 2017)

10. UN GA (2-15) Transforming our world: The 2030 agenda for sustainable development (A/RES/70/1) (UN General Assembly, New York, 2017)

11. V. Kopein, E. Filimonova, I. Kudryashova, K. Demidenko, E3S Web Conf., 41, 04036 (2018)

12. M. Capriati, Innovations and Development, 3:1, 1-17 (2013) 